\title{
Talk the talk and walk the walk. Evaluation of autonomy in aging and Alzheimer Disease by simulating instrumental activities of daily living: The S-IADL
}

\author{
Véronique Quaglino ${ }^{\text {Corresp... }}{ }^{1}$, Yannick Gounden ${ }^{1}$, Emilie Lacot ${ }^{1,2}$, Frédérique Couvillers ${ }^{3}$, Amandine Lions ${ }^{4}$, \\ Mathieu Hainselin ${ }^{1}$ \\ 1 Université de Picardie Jules Verne, CRPCPO, EA 7273, Amiens, France \\ 2 Service de Génétique Clinique et Oncogénétique, Centre Hospitalier Universitaire d'Amiens Picardie, Amiens, France \\ ${ }^{3}$ Services de neurologie et de gérontologie, Centre Hospitalier Universitaire d'Amiens Picardie, Amiens, France \\ 4 IME Les Martinets, Adapei 36 I'Espoir, Saint Maur, France \\ Corresponding Author: Véronique Quaglino \\ Email address: veronique.quaglino@u-picardie.fr
}

Objective: The autonomy of individuals is linked to the achievement of instrumental activities of daily living that require complex behavior. In elderly, the assessment of autonomy is usually based on questionnaires that have strong subjective constraints. Considering this fact, we tested on elderly healthy adults and Alzheimer disease patients, a new measure, the S-IADL (Simulation of Instrumental Activities for Daily Living) to assess the ability to perform effectively activities of daily living.

Method: The S-IADL shares many items with the well-known IADL questionnaire proposed by Lawton and Brody (1969). However, as opposed to the IADL, the assessment of autonomy is not based on the completion of a questionnaire but requires the realization or simulation of various activities of daily living. Eighty-three participants (69 healthy elderly, and 14 Alzheimer Disease patients) completed the IADL and performed the S-IADL assessment.

Results: Results revealed that like the IADL, the S-IADL is able to identify AD patients who are likely to encounter difficulties in performing everyday activities, and no major differences were found between the IADL and the S-IADL.

Conclusions: We outlined some advantages for prefering, in certain situation, this new tool based on simulation of activities in functional evaluation. Finally, we discuss the main limits of the S-IADL that should be investigated prior to its utilization by clinicians. 
1 Talk the talk and walk the walk. Evaluation of autonomy in aging and Alzheimer

2 Disease by simulating instrumental activities of daily living: The S-IADL

3 Véronique QUAGLINO1, Yannick GOUNDEN1', Emilie LACOT1,2, Frédérique

4 COUVILLERS ${ }^{3}$, Amandine LIONS ${ }^{4}$, Mathieu HAINSELIN ${ }^{1}$

5

$6 \quad{ }^{1}$ CRPCPO, EA 7273, Université de Picardie Jules Verne, Amiens, France

$7 \quad{ }^{2}$ Centre Hospitalier Universitaire d'Amiens Picardie, Service de Génétique Clinique et

8 Oncogénétique, Amiens, France

$9{ }^{3}$ Centre Hospitalier Universitaire d'Amiens Picardie, Services de Neurologie et de

10 Gérontologie, Amiens, France

$11{ }^{4}$ IME Les Martinets, ADAPEI 3636 I'Espoir, Saint Maur, France

14 Correspondence should be addressed to:

15 Véronique QUAGLINO

16 Centre de Recherche en Psychologie : Cognition, Psychisme, et Organisations 17 (CRPCPO, EA7273)

18 Université de Picardie Jules Verne

19 Chemin du Thil - 80025 Amiens Cedex 1, France

20 veronique.quaglino@u-picardie.fr

21 Tél. : +33 322827410

22 Fax: +33322827408 
Abstract

Objective: The autonomy of individuals is linked to the achievement of instrumental activities of daily living that require complex behavior. In elderly, the assessment of autonomy is usually based on questionnaires that have strong subjective constraints. Considering this fact, we tested on elderly healthy adults and Alzheimer disease patients, a new measure, the S-IADL (Simulation of Instrumental Activities for Daily Living) to assess the ability to perform effectively activities of daily living. proposed by Lawton and Brody (1969). However, as opposed to the IADL, the assessment of autonomy is not based on the completion of a questionnaire but requires the realization or simulation of various activities of daily living. Eighty-three participants (69 healthy elderly, and 14 Alzheimer Disease patients) completed the IADL and performed the S-IADL assessment.

Results: Results revealed that like the IADL, the S-IADL is able to identify AD patients who are likely to encounter difficulties in performing everyday activities, and no major differences were found between the IADL and the S-IADL. new tool based on simulation of activities in functional evaluation. Finally, we discuss the main limits of the S-IADL that should be investigated prior to its utilization by clinicians. 


\section{INTRODUCTION}

49

50

51

52

53

54

55

56

57

58

59

60

61

62

63

64

65

66

67

68

69

70

The present study concerns the estimation of personal autonomy in aging and Alzheimer disease. More precisely, instead of using typical self-evaluation questionnaires, we devised a new tool to evaluate individuals' capacity in performing common activities of daily living. Two considerations guided this new tool proposal. First, the evaluation of autonomy must reflect to some extent, the real life of the person and secondly, it should not rely solely on the appreciation of the patient and caregivers who may not always be objective. We thus proposed a new tool which accesses autonomy through the simulation of daily living activities.

Autonomy is a systemic and multidimensional entity which encompasses sensorimotor, psychosocial, cognitive and medical aspects (Eghbal-Téhérani \& Makdessi, 2011). Physical activity, social relationships, psychological well-being and cognitive functioning are thus among the many factors that can give an insight on an individual's degree of autonomy. The term functional autonomy refers to the ability to perform activities of daily living (ADL) (Perrig-Chiello, Perrig, Uebelbacher, \& Stähelin, 2006), at different levels: basic activities (eating, moving, toileting or shower/bath taking) and more complex instrumental activities (medication taking, shopping or managing a budget). These instrumental activities of daily living (IADL) require good organizational, judgment and sequencing abilities (Royall, Chiodo, \& Polk, 2000). The loss of functional autonomy is generally the result of an imbalance between the functional capacities of an individual and the social and material resources available. Functional autonomy generally decreases with aging, as a consequence of the wide range of physical, cognitive, emotional, and/or social changes. This lost in autonomy is even more important for people 
71 with Alzheimer Disease (Jekel et al., 2015). However, these changes being characterized

72 by interindividual heterogeneity, the assessment of elderly people's functional autonomy

73 should therefore be specific and personalized in order to target their needs and to develop

74 appropriate services. This kind of assessment is to our knowledge problematic due to a 75 lack of appropriate tools for an efficient evaluation of functional autonomy in elderly adults. In France, the AGGIR (Autonomie Gérontologie Groupes Iso-Ressources for

77 Autonomy Gerontology Groups Iso-Resources) grid is commonly used to assess the degree of dependence of a person by classifying him or her, in one of the 6 categories (GIR 1 to GIR 6). Personal Autonomy Allowance (PAA) is granted to dependent older people classified in the first 4 GIR groups. People classified in GIR 1 are considered to be in the highest dependency and are thus allotted more help, while people classified in GIR 4 have the lowest help (Bontout, Colin, \& Kerjosse 2002). In 2000, the HandicapIncapacity-Dependency survey found that 530,000 elderlies out of the 12.1 millions of people aged over 60 years were classified in the GIR 1 category (Colin \& Coutton, 2000). This data highlights the importance of developing specific tools for evaluating the autonomy of our elders who might be assigned to the same particular category while encountering their own specific difficulties with regard to autonomy.

The ADL scale (Katz et al., 1970) and the IADL questionnaire from Lawton and Brody (1969) assesses respectively the capacity of an individual to perform common ADL 91 (body care, dressing, toileting, transferring, feeding...) and complex IADL (such as using 92 the telephone, shopping, preparing meals, cleaning, washing clothes, using public 93 transport, managing drug intake or a budget...). These tools are widely and frequently 
94 used in clinical practice and research (Martyr \& Clare, 2012). In France, the IADL is even

95 recommended by the National Authority for Health (HAS: Haute Autorité de Santé), an

96 independent public scientific authority with an overall mission of contributing to the 97 regulation of the healthcare system by improving health quality and efficiency. Various 98 studies have also confirmed its reliability and usefulness. For instance, the French 99 PAQUID study (Barberger-Gateau et al., 1999; Pérès et al., 2008) showed that the degree 100 of dependence as measured by the IADL self-report questionnaire, mostly with 4 items 101 (ability to use telephone, mode of transport, responsibility for own medication and ability 102 to handle finances), could be a good predictor of the risk of developing dementia. More 103 specifically, cognitive performances assessed by neuropsychological tests appear to be 104 closely linked to the functional autonomy of individuals (Perrig-Chiello et al., 2006; 105 Tomaszewski Farias, Cahn-Weiner, Harvey, Reed, Mungas, \& Chui, 2009). More 106 recently, it was also found that attentional, memory, language, and visuospatial capacities 107 correlated with the scores obtained at the IADL questionnaire specifically for telephone usage, drug taking and budget management (Millán-Calenti et al., 2012). However, these assessments are limited mostly to people aged under 80 years (Jekel et al., 2015). Although the IADL has proved its efficacy, this evaluation of daily life autonomy 111 suffers mainly from the absence of execution in real life context. Indeed, this self112 assessment scale is presented in the form of a subjective self-report questionnaire and it 113 requires the individual to be able to estimate his or her own functioning and abilities in using effective strategies when solving a particular task (Juillerat Van der Linden, 2008).

115 Metacognitive monitoring skills, which are demanding in terms of executive functions, are 116 usually impaired in aging (Douchemane, Isingrini, \& Souchay, 2007; Souchay, Isingrini, 
117 Clarys, Taconnat, \& Eustache, 2004). These monitoring capacities are nevertheless

118 particularly involved in various aspects of daily living activities (Buckley, Norton,

119 Deberard, Welsh-Bohmer, \& Tschanz, 2010; Mascherek, Zimprich, Rupprecht, \& Lang,

120 2011; Mol, Boxtel, Willems, \& Jolles, 2006). For example, in Alzheimer disease (AD),

121 including the mild stage, patients besides showing a lack of awareness with regard to

122 their deficits (Morris \& Mograbi, 2013; Starkstein et al., 1997), also have a tendency to

123 underestimate their deficits in activities of daily living. It is worth noticing that a meta-

124 analysis showed no difference in the effect sizes between self-rated and informant-rated

125 functional ability and executive function (Martyr \& Clare, 2012).

126

Numerous alternatives to the IADL or to similar self/informant report questionnaires

127

exist. For instance, a variety of performance-based measures have been devised over

128

the past 25 years, such as the (Revised) Direct Assessment of Functional Status (DAFS;

McDougall, Becker, Vaughan, Acee, \& Delville, 2010). These tools consist in presenting

130

examinees with functional tasks in a standardized format. As an illustration, instead of

questioning the patient on his or her cooking skills, the latter is required to prepare a meal

using a mock kitchen within the hospital compound. However, this method of assessing

functional autonomy is generally time consuming and may require a considerable

134 financial investment on certain materials. The Assessment of Motor and Process Skills

135 (AMPS) for example, is one of the best known and widely used standardized

assessments which measures the quality of a person's motor and process skill performance through therapist observation of everyday tasks. However, the use of this

139 for training are continually reducing to the point of being nonexistent in some areas. 
140 Added to this, as noted by Wenborn (2007), it is also difficult for many users to have their

141 employers investing in the updated software of the AMPS. The potential range of barriers

142 to effective implementation of the AMPS have previously been well described by (Chard,

1432000 , 2004). Finally, like most existing tools, the AMPS to our knowledge has not yet

144 been implemented for a French speaking population.

145 Taking into consideration the French context, where the use of IADL is well 146 established despite its various limits as outlined above (Sikkes \& Rotrou, 2014), we 147 proposed to create another complementary version of this tool. We took into consideration 148 the main requests of clinicians that is, a tool which does not require a long training, not 149 expensive in implementing and that can be rapidly administered during a consultation.

150 151

152 153

154 155

We thus developed the S-IADL (Simulation of Instrumental Activities of Daily Living) which includes similar items to those of the IADL (Lawton \& Brody, 1969). However, unlike the IADL, participants are required to simulate the activities and in doing so, this new tool aims at overcoming the limitations of traditional assessments that we have outlined above. This study aims at matching IADL and S-IADL performances for both healthy elderly (HE) participants and $A D$ patients and to compare their sensitivity and specificity at their optimal cut-off points for the sample investigated.

\section{METHODS}

Participants

Eighty-three participants took part in this study: 69 healthy elderly (HE), and 14 Alzheimer Disease patients (AD). All participants were French native speakers, aged between 61 and 90 years old. They could all read, write, and understand correctly. 
The $69 \mathrm{HE}$ (including 37 women, 53.62\%) were retired volunteers leading active 165 lives. They were all seen at their own houses. HE with previous or current neurological or psychiatric disorders, sensory or motor impairments, and severe cardiac, respiratory or

167

168

169

170

171

172

173

174

175

176

177

178

179

180

181

182

183

184

185

186

renal failure were excluded. The 14 AD patients (including 5 women, $35.71 \%$ ) were recruited from day care centers. All of them previously underwent a complete diagnostic procedure conducted by a physician specialized in geriatrics and met the clinical criteria for probable AD according to the DSM-IV (American Psychiatric Association, 1994). The $A D$ patients were seen in their day care center. They were all fully cooperative and none of them exhibited behavioral disturbances. The following criteria were also considered when selecting $A D$ patients: apart from the $A D$, no other previous or current neurological or psychiatric disorders, sensory or motor impairments, severe cardiac, respiratory or renal failure. The Mini Mental State Examination (MMSE) (Kalafat, Hugonot-Diener, \& Poitrenaud, 2003), the Goldberg's anxiety Scale (Goldberg, Bridges, Duncan-Jones, \& Grayson, 1988) and the Beck Depression Inventory (BDI-II) (Beck, Steer, Ball, \& Ranieri, 1996) were administered according to standard procedures to all participants. The characteristics of the two groups are shown in table 1.

$\underline{\text { Material }}$

The Instrumental Activities of Daily Living questionnaire (IADL), translated in French by Israel and Waintraub (1986), was used (Lawton \& Brody, 1969). This 
187 questionnaire includes eight questions on people's abilities to use Telephone, to perform 188 Shopping, to prepare Meals, to maintain Cleaning, to do Laundry, to use Transport, to 189 take Medications, and to manage Budget. The performance for each subtest of the IADL 190 is estimated from 0 to 4 . The total score is thus 32 points.

By referring to the IADL, we developed the S-IADL to simulate various instrumental 192 daily living activities. The 13 activities of the S-IADL are likely to be representative of the 193 those performed by elderly adults (see Table 2 for details): planning a Day; making a 194 Shopping list; opening Hours of shops; using the Telephone; paying a bill by Check; 195 writing an address on an Envelope; planning how to relay point $\mathrm{A}$ to point $\mathrm{B}$ using a Bus 196 S- IADL is estimated from 0 to 4 points and the total score is thus 52 points.

To score, the examiner referred to an observation checklist to identify the 205 strategies used, the difficulties encountered and also the strategies devised by the person 206 to cope with these difficulties: corrects himself or herself alone; 
1 point, partial success: the individual performs the action correctly when the examiner

210

217

212

213

214

215

216

217

218

219

220

221

222

223

224

225

226

227

228

229

230

231 reported his or her error;

2 points, help with success: the individual can achieve single action, but he/she succeeds with the help of the examiner;

3 points, failure even with aid: the execution is unsuccessful even with the help of the examiner;

4 points, failure: the execution is impossible or not evaluable.

For the two questionnaires, IADL and S-IADL, the higher the score is, the less the individual is autonomous.

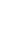

\section{Design}

The factors considered in this study corresponded to a 2 (group: HE and AD) x 2 (evaluation: IADL and S-IADL). The first factor was varied among participants and the second one was a within-participants factor.

\section{Procedure}

The study was conducted in accordance with the ethical guidelines for research in psychology and with the ethical principles of psychologists and code of conduct. The HE adults were contacted by phone and, after a brief explanation of the theme of the study, an appointment was set up. Each participant was then seen at home by a clinical psychologist. With the aid of an anamnestic questionnaire, a meticulous screening of the HE adults' general medical history was then performed. Concerning the AD patients, they were seen individually at their day care centers by the same clinical psychologist as for 
232 the HE adults. In order to enable participants to make an informed decision as to whether

233 or not they wish to participate, they were asked to read and sign a consent form which

234 stated the purpose of the study, what is expected from them, the length of time, the 235 possibility of withdrawal at any time and also the guarantee of confidentiality and 236 anonymity of personal data. The study was carried out according to the local Ethics 237 Committee for Health Research.

238 Each participant was assessed, in the same order, with the following evaluations:

The Mini Mental State Examination (MMSE, Kalafat et al., 2003), the Goldberg's anxiety 240 Scale (Goldberg et al., 1988) and the Beck Depression Inventory (BDI-II, Beck et al., 24 1961). The IADL was then administered as a self-assessment scale, followed by the S242 IADL. The clinical psychologist paid attention to the strategies used by the participants, 243 the difficulties encountered and the palliative solutions that they deployed to overcome 244 these difficulties. Overall, the experimental procedure lasted for about $1 \mathrm{~h} 30$ and 245 participants were given the possibility to take a break when needed.

\section{RESULTS}

Descriptive data (means proportions and standard deviation of the IADL and S250 IADL scores) are presented in table 1 and were compared using a Student's 2-sample $t$ 251 tests with $5 \%$ as error rate level. Each total score was transformed into a success rate 252 (percentage). Note that the higher the score is the less the individual is autonomous. As 253 expected, HE obtained better performances at both tools (IADL $M=30.9$; S-IADL $M=$

9.7) than AD patients (IADL $M=49.77 ;$ S-IADL $M=28.71$ ). 
The sample of HE adults being younger than the AD patients, an ANCOVA was

256

257

258

259

260

261

262

263

264

265

266

267

268

269

270

271

272

273

274

275

276

277

conducted to control the confounding age factor (Table 3 and Appendix). Results showed

a significant difference in IADL score between the two groups when adjusted for age [ $F$ $(1,82)=28.52, p<.001, \eta 2=.26]$. Regarding the estimation of the effect size, the partial eta-square coefficient is large explaining $26 \%$ of the variance (Cohen, 1988). For the SIADL scores, the ANCOVA revealed that there was also significant difference between the two participant groups when adjusted for age $[F(1,82)=13.31, p<.001, \eta 2=.14]$. Concerning the estimation of the effect size, the partial eta-square coefficient is large explaining $14 \%$ of the variance.

A Receiver Operating Characteristic (ROC) curve analysis was performed to estimate the optimal cut-off value for both questionnaires and to determine the ability of each to discriminate between groups, AD patients and HE adults (see Figure 1). We also compared the performances at both IADL and the S-IADL questionnaires, by evaluating the areas under the curve (AUC). The AUC of the questionnaire was significantly different from the AUC corresponding to a random test. In order to determine their specificity and sensitivity for establishing their cut-off points, we searched for significant differences between the AUCs. We ended our analysis by comparing the sensitivity and specificity of the two questionnaires with their established cut-off points. In analyzing our results, we first checked whether the AUC of the two questionnaires was significantly different from the area under the diagonal determined of a random test. Table 3 presents the results of this analysis for the IADL and S-IADL questionnaires. As shown in the table, the test revealed a significant difference from the random area, with a probability of error smaller than $0.1 \%(p<.001)$. 

sensitivity and specificity at each possible cut-off point. The best performance of the IADL 289 in discriminating between HE and AD participants, is reached at the cut-off point of 41.94 290 (sensitivity $=86$; specificity $=91$ ). Note that this cut-off point has to be considered as the success rate that allows dissociating between a deficiency and a non-deficiency 292 performance. For the S-IADL, results indicated that the best discriminating performance is reached at the cut-off point of 14.98 (sensitivity = 93; specificity = 81).

294

\section{DISCUSSION}

The IADL is a self-assessment scale and is presented in the form of a subjective self-report questionnaire while the S-IADL, requires an active participation to simulate the same activities as the IADL.

As expected, HE participants were better than AD patients in both the S-IADL and 300 the IADL, even when age (as covariate factor) is adjusted. However, contrary to our 
301 expectations, this pattern of results was not significantly different across the two 302 questionnaires. Our results also revealed that both the IADL and S-IADL questionnaires 303 are able to identify $A D$ patients who are likely to encounter difficulties in performing 304 everyday activities. A high discriminative capacity was also found for the two 305 questionnaires. It suggests that, for both HE adults and AD patients, responses at the 306 IADL and performances at the S-IADL questionnaires were significantly different from 307 what could be obtained at a random test. These two questionnaires have thus a high 308 accuracy in identifying AD patients who might be losing autonomy in everyday activities. By referring to the accuracy of both questionnaires at their optimum cut-off point, 310 it appeared that the S-IADL has a better sensitivity (93 vs. 86) than the IADL while the 311 IADL has a better specificity than the S-IADL (91 vs. 81). However, it is difficult at this 312 point to draw any conclusion on these minimal differences. Further research is needed to 313 confirm results for this preliminary study. If this pattern of results with regard to sensitivity 314 and specificity is real, this would mean that the S-IADL and the IADL are complementary 315 tools which could be preferred depending on the clinician's objectives.

The S-IADL is another step towards a more ecological way to assess patients' 317 abilities and autonomy in a classical context of evaluation (i.e. without going to the 318 person's home). Although in the present study no major differences were obtained 319 between the classical IADL and the S-IADL, in certain situations it may be worth preferring 320 our new tool. For instance, it may give clinicians the possibility to identify why an activity 321 is difficult to perform, how the person copes with his or her difficulties in order to perform 322 the activity and what can be proposed as specific compensatory strategies. 323 

cognitive assessment (Agrigoroaei \& Lachman, 2011; Soederberg Miller \& Lachman, 326 2000) and can have considerable impacts on daily activities. In the first case, due to low self-esteem or lack of self-confidence, some ageing adults may feel that they are no more able to perform on their own certain daily living activities that they actually can. Inversely in the second case, not knowing that a deficit exists may make problematic for people to 330 accept assistance (Cott \& Tierney, 2013). Consequently, it is not rare to have a patient exposed to serious dangers by performing at home, activities that should not be performed alone. However, it should be noted that a few studies have also shown that people with dementia may be aware of their own IADL ability (Kiyak, Teri, \& Borson, 1994; Marková et al., 2014; Martyr, Nelis, \& Clare, 2014). Awareness literature often focused on discrepancy scores between self and informant ratings, but failed to take into account all of the confounding variables influencing the reliability of the informant. For instance; recent studies show that caregiver burden, informant depression, age and cognitive status of the patient, are among the many factors associated with rating bias (Martyr et al., 2014; Sikkes \& Rotrou, 2014).

With regard to these two issues, the S-IADL can be an appropriate tool since it does not rely on subjective evaluations of patients and informants but rather places patients in an active position where they can be exposed to what really they can do or not 343 In the present study, no measure of awareness or self-esteem, was conducted. However, 344 considering the coherence between the IADL and the S-ADL, it is possible that overall, 345 our participants have a good awareness of their actual capacities in daily living activities. 
346 Indeed, the AD patients were all at an early stage and did not present a serious

347 deterioration of their global intellectual capacities (see MMSE score).

In the very early stages of $A D$, a combination of the IADL and the S-IADL might be useful especially when patients have low self-esteem with regard to their abilities in daily 350 life activities. In later stages particularly when patients suffer from acute lack of awareness, the S-IADL may be more appropriate in assessing autonomy in everyday life 352 activities.

However, further studies need to examine the relations between the degree of 354 awareness or self-esteem with performances at both the IADL (what I think I can do) and 355 the S-IADL (what I can actually do).

By using a specific grid, the S-IADL allows clinicians to gather more and multimodal 357 information while patients are performing the actions. They can have a more precise idea of which specific step in the process is a problem and identify strategies which may be effective or not. All this information, unavailable with questionnaires, should help clinicians not only for diagnosis purposes but also for rehabilitation.

Another strength of the S-IADL, is the possibility to adjust items to a particular patient considering his/her actual activities. Besides the 13 activities described here, we can imagine adding gardening or sewing or any other daily activity that the person performs.

364 This flexibility of the S-IADL, is in line with the need to develop personalised care and 365 support for patients.

Naturally, there are also some limitations to the S-IADL which must be resolved before proposing it to clinicians. Beside the need to test the S-IADL on a bigger sample, 
368 as suggested above we also need to include patients with and without deficit awareness

369 and see whether performances would be different between the IADL and the S-IADL.

370 Most importantly, it will also be necessary to verify that performances of a person with the

371 S-IADL, really reflect his or her abilities in real life. Indeed, one can be in difficulty in daily

372 living activities for various reasons such as cognitive and or motor impairments. Success

373 or failure in the S-IADL is more likely to rely on the efficiency of cognitive functions and

374 only to some extent on motor abilities, since patients are requested only to simulate the

375 activities. Thus, although confirmation is needed, we can expect that someone who

376 encounters difficulties in performing the S-IADL will also encounter difficulties in

377 cognitively more complex real life situations. However, we will be more prudent in

378 suggesting that a person, who succeeds in the S-IADL, is also able to perform with the

379 same ease daily living activities in real life. Hence, like the various tests at the disposal of

380 clinicians, the S-IADL is only a tool which can give some important indications on one's

381 autonomy in performing daily living activities but is not sufficient on its own. It can be used

382 in complementary with the IADL and a thorough interview of the patient and his or her 383 relatives.

384 The IADL scale has been widely criticized for being strongly biased towards men 385 since many of the items are based around traditional female gender roles. This potential 386 gender bias of the Lawton IADL Scale has led to the generation of some non-validated 387 adaptations for its application in men (Vergara et al., 2012). Investigating a possible 388 gender effect with the S-IADL is thus of upmost importance prior to its utilization by 389 clinicians. Finally, although the IADL is known to have reasonably good cross-cultural 390 validity (Ng, Niti, Chiam, \& Kua, 2006), further research should also test the cross-cultural 
391 applicability of the simulation version across ethnic groups and if possible in conjunction 392 with gender.

393 Acknowledgments: We would like to thank all participants. Also we are grateful to Camille 394 GAUDET, Marine WALTON, Alexandra BENOIST and Sophia BENQUET, students in 395 Neuropsychology at Picardie Jules Verne University (Amiens, France) who contributed to 396 data collection

397

398

\section{REFERENCES}

American Psychiatric Association (1994) Diagnostic and Statistical Manual of Mental Disorders. 4. Washington, DC: American Psychiatric Association.

Barberger-Gateau, P., Fabrigoule, C., Helmer, C., Rouch, I., Letenneur, L., \& Dartigues, J. F. (1999). Functional impairment in instrumental activities of daily living: an early clinical sign of dementia? Journal of the American Geriatrics Society, 47(4), 456-62.

Beck AT, Steer RA, Ball R, Ranieri W (1996). Comparison of Beck Depression Inventories -IA and -II in psychiatric outpatients. Journal of Personality Assessment, 67 (3), 58897. doi:10.1207/s15327752jpa6703_13

Bontout, O., Colin, C. \& Kerjosse, R. (2002). Personnes âgées dépendantes et aidants potentiels : une projection à l'horizon 2040. Direction de la Recherche des Etudes de l'Evaluation et des Statistiques (DREES), Etudes et Résultats, 160 (12), 1-11.

Buckley, T., Norton, M. C., Deberard, M. S., Welsh-Bohmer, K. A., \& Tschanz, J. T. (2010). A brief metacognition questionnaire for the elderly: comparison with cognitive performance and informant ratings the Cache County Study. International Journal of Geriatric Psychiatry, 25 (7), 739-47. doi:10.1002/gps.2416 
414 Cavanaugh, J. C., \& Blanchard-Fields, F. (2006). Adult Development and Aging (5th

$415 \quad$ Ed.), Belmont, CA: Wadsworth/Thomson Learning

416 Chard, G. (2000). An investigation into the use of the Assessment of Motor and Process

417 Skills (AMPS) in clinical practice. British Journal of Occupational Therapy.

418 Chard, G. (2004). Implementing the Assessment of Motor and Process Skills (AMPS) in

419 the workplace: A comparison of the experiences of occupational therapists and new

420 graduates. British Journal of Occupational Therapy, 67(2), 54-64.

421

doi:10.1177/030802260406700202

422 Cohen, J (1988) Statistical power analysis for the behavioral sciences (2nd ed.).

$423 \quad$ Hillsdale, NJ: Erlbaum.

424 Colin, C., \& Coutton, V. (2000). Le nombre de personnes âgées dépendantes d'après

425 I'enquête Handicap-Incapacités-Dépendance. Direction de la Recherche des 426 Etudes de l'Evaluation et des Statistiques (DREES), Etudes et Résultats, 94, 1-8.

427 Douchemane, D., Isingrini, M., \& Souchay, C. (2007). Vieillissement, fonctions 428 exécutives et métamémoire : dissociation entre le feeling-of-knowing (sentiment de 429 savoir) en mémoire épisodique et en mémoire sémantique. L'Année Psychologique, 107, 597-622.

431 Eghbal-Téhérani, S., \& Makdessi, Y. (2011). Les estimations GIR dans les enquêtes 432 Handicap-Santé : Méthode de calcul, intérêt et limites d'une estimation en population

435 Goldberg, D., Bridges, K., Duncan-Jones, P., \& Grayson, D. (1988). Detecting anxiety 436 générale. Direction de la recherche, des études, de l'évaluation et des statistiques DREES. and depression in general medical settings. British Medical Journal, 29, 897-899. 
437 Hébert, R. (1997). Functional decline in old age. Canadian Medical Association Journal, $438 \quad 157(8), 1037-45$.

439 Jekel, K., Damian, M., Wattmo, C., Hausner, L., Bullock, R., Connelly, P. J., .. Frölich, L. 440 (2015). Mild cognitive impairment and deficits in instrumental activities of daily living: $441 \quad$ a systematic review. Alzheimer's Research \& Therapy, 7(1). doi:10.1186/s13195$442 \quad 015-0099-0$

443 Juillerat Van der Linden, A.-C. (2008). Démence de type Alzheimer et évaluation des 444 activités de la vie quotidienne. In M. Van der Linden, A.-C. Juillerat Van der Linden, $445 \quad$ G. Aubin, and D. Le Gall (Eds.), Neuropsychologie de la Vie Quotidienne (pp. 41446 105). Marseille: Solal.

447 Kalafat M, Hugonot-Diener L, \& Poitrenaud J. (2003). Standardisation et étalonnage 448 français du « Mini Mental State » (MMS) version GRECO. La Revue de $449 \quad$ Neuropsychologie, 13 (2), 209-236.

450 Katz, S., Downs, T. D., Cash, H. R., \& Grotz, R. C. (1970). Progress in development of 451 the index of ADL. The Gerontologist, 10(1), 20-30.

452 Kiyak, H. A., Teri, L., \& Borson, S. (1994). Physical and functional health assessment in 453 normal aging and in Alzheimer's disease: self-reports vs family reports. The $454 \quad$ Gerontologist, 34(3), 324-30.

455 Lawton, M. P., \& Brody, E. M. (1969). Assessment of older people: self-maintaining and $456 \quad$ instrumental activities of daily living. The Gerontologist, 9(3), 179-86.

457 Marková, I. S., Clare, L., Whitaker, C. J., Roth, I., Nelis, S. M., Martyr, A., ... Morris, R. 458 (2014). Phenomena of awareness in dementia: Heterogeneity and its implications. 459 Consciousness and Cognition, 25(1), 17-26. doi:10.1016/j.concog.2014.01.008 
460 Martyr, A., \& Clare, L. (2012). Executive Function and Activities of Daily Living in 461 Alzheimer's Disease: A Correlational Meta-Analysis. Dementia and Geriatric 462 Cognitive Disorders, 33(2-3), 189-203. http://doi.org/10.1159/000338233

463 Martyr, A., Nelis, S. M., \& Clare, L. (2014). Predictors of perceived functional ability in 464 early-stage dementia: self-ratings, informant ratings and discrepancy scores. 465 International Journal of Geriatric Psychiatry, 29(8), 852-862. doi:10.1002/gps.4071 466 Mascherek, A., Zimprich, D., Rupprecht, R., \& Lang, F. R. (2011). What Do Cognitive 467 Complaints in a Sample of Memory Clinic Outpatients Reflect? The Journal of 468 Gerontopsychology and Geriatric Psychiatry, 24(4), 187-195. doi:10.1024/1662$9647 / a 000046$

470

471

472

473

474

475

476

477

478

479

480

481

482

McDougall, G. J., Becker, H., Vaughan, P. W., Acee, T. W., \& Delville, C. L. (2010). The Revised Direct Assessment of Functional Status for Independent Older Adults. The Gerontologist, 50(3), 363-370. http://doi.org/10.1093/geront/gnp139

Millán-Calenti, J. C., Tubío, J., Pita-Fernández, S., Rochette, S., Lorenzo, T., \& Maseda, A. (2012). Cognitive impairment as predictor of functional dependence in an elderly sample. Archives of Gerontology and Geriatrics, 54(1), 197-201. doi:10.1016/j.archger.2011.02.010

Mol, M. E. M., Boxtel, M. P. J. Van, Willems, D., \& Jolles, J. (2006). Do subjective memory complaints predict cognitive dysfunction over time? A six-year follow-up of the Maastricht Aging Study, (4), 432-441.

Moore, D. J., Palmer, B. W., Patterson, T. L., \& Jeste, D. V. (2007). A review of performance-based measures of functional living skills. Journal of Psychiatric Research, 41(1-2), 97-118. doi:10.1016/j.jpsychires.2005.10.008 
483 Morris, R. G., \& Mograbi, D. C. (2013). Anosognosia, autobiographical memory and self484 knowledge in Alzheimer's disease. Cortex, 49(6), 1553-65. 485 doi:10.1016/j.cortex.2012.09.006

486 Ng, T.-P., Niti, M., Chiam, P.-C., \& Kua, E.-H. (2006). Physical and cognitive domains of 487 the Instrumental Activities of Daily Living: validation in a multiethnic population of 488 Asian older adults. The Journals of Gerontology. Series A, Biological Sciences and 489 Medical Sciences, 61(7), 726-735. doi:http://dx.doi.org/10.1093/gerona/61.7.726

Peres, K., Helmer, C., Amieva, H., Orgogozo, J.-M., Rouch, I., Dartigues, J.-F., \& 491 Barberger-Gateau, P. (2008). Natural History of Decline in Instrumental Activities of 492 Daily Living Performance over the 10 Years Preceding the Clinical Diagnosis of Dementia: A Prospective Population-Based Study. Journal of the American Geriatrics Society, 56(1), 37-44. http://doi.org/10.1111/j.1532-5415.2007.01499.x

Perrig-Chiello, P., Perrig, W. J., Uebelbacher, A., \& Stähelin, H. B. (2006). Impact of physical and psychological resources on functional autonomy in old age. Psychology, Health \& Medicine, 11 (4), 470-82. Doi:10.1080/13548500600726633

Royall, D.R., Chiodo, L.K., \& Polk, M. J. (2000). Correlates of disability among elderly retirees with "subclinical" cognitive impairment. Journal of Gerontology, 55 (9), 541 546

Sikkes, S. A. M., \& Rotrou, J. de. (2014). A qualitative review of instrumental activities of daily living in dementia: what's cooking? Neurodegenerative Disease Management, 4(5), 393-400. doi:10.2217/nmt.14.24 
504 Souchay, C., Isingrini, M., Clarys, D., Taconnat, L., \& Eustache, F. (2004). Executive 505 functioning and judgment-of-learning versus feeling-of-knowing in older adults. 506 Experimental Aging Research, 30 (1), 47-62. doi:10.1080/03610730490251478

507 Starkstein, S. E., Chemerinski, E., Sabe, L., Kuzis, G., Petracca, G., Tesón, A., \& 508 Leiguarda, R. (1997). Prospective longitudinal study of depression and anosognosia 509 in Alzheimer's disease. The British Journal of Psychiatry: The Journal of Mental $510 \quad$ Science, $171,47-52$.

511 Tomaszewski Farias, S., Cahn-Weiner D.A., Harvey, D.J., Reed, B.R., Mungas, D., \& 512 Chui, H. (2009). Longitudinal changes in memory and executive functioning are 513 associated with longitudinal changes in instrumental activities of daily living in older 514 adults. The Clinical Neuropsychologist, 23 (3), 446-61. 515 doi: $10.1080 / 13854040802360558$

516 Vergara, I., Bilbao, A., Orive, M., Garcia-Gutierrez, S., Navarro, G., \& Quintana, J. M. 517 (2012). Validation of the Spanish version of the Lawton IADL Scale for its 518 application in elderly people. Health and Quality of Life Outcomes, 10, 130. 519 doi:10.1186/1477-7525-10-130

520 Wenborn, J. (2007). Commentary on "A critique of the Assessment of Motor and 521 Process Skills (AMPS) in mental health practice". Mental Health Occupational 522 Therapy, 12(1), 8-9.

523 
524 Table 1: Characteristics of the two groups of participants with T-Test and $p$-value 525 comparisons

526

\begin{tabular}{|c|c|c|c|}
\hline & \multicolumn{2}{|c|}{ Group } & \multirow[t]{2}{*}{$T$-test, $p$ value } \\
\hline & $\mathrm{AD}(N=14)$ & $\mathrm{HE}(N=69)$ & \\
\hline Age & $75-90(M=84)$ & $61-90(M=73)$ & - \\
\hline MMSE & $23-18 ; M=20.14(1.99)$ & $30-22 ; M=27.38(2.05)$ & $T=12.31, p<.001$ \\
\hline BDI & 6 ; 2.21 (1.97) & $0-19 ; 4.16(4.34)$ & $T=1.63, \mathrm{~N} . \mathrm{S}$ \\
\hline Goldberg & $.79(1.48)$ & $8-0 ; M=2.04(2.46)$ & $T=1.84, \mathrm{~N} . \mathrm{S}$ \\
\hline IADL & $65-29 ; M=49.76(10.64)$ & $61-26 ; M=30.9(7.69)$ & $T=-6.31, p<.001$ \\
\hline S-IADL & $51-8 ; M=28.71(13.49)$ & $61-0 ; M=9.7(9.67)$ & $T=-5.02, p<.001$ \\
\hline
\end{tabular}

\section{7}

528 Range score; Mean and standard deviation for the tests and comparisons between 529 groups of participants (AD for Alzheimer Disease and HE for Healthy Elderly) using $T$-test 530 and $p$-value 
532 Table 2: S-IADL items and their description

\begin{tabular}{|c|c|c|}
\hline S-IADL Items & & IADL items \\
\hline $\begin{array}{l}\text { 1-Planning a } \\
\text { Day }\end{array}$ & $\begin{array}{l}\text { Organize a typical day by } \\
\text { matching activities written on } \\
\text { labels with a particular time of the } \\
\text { day. This item is composed of a } \\
\text { board with schedules for a day and } \\
10 \text { labels. }\end{array}$ & I \\
\hline $\begin{array}{l}2 \text { - Making a } \\
\text { Shopping list }\end{array}$ & $\begin{array}{l}\text { Make a list of groceries to buy for } \\
\text { a determine number of relatives in } \\
\text { order to be able to eat during two } \\
\text { days }\end{array}$ & Shopping \\
\hline $\begin{array}{l}\text { 3- Opening } \\
\text { hours of shops }\end{array}$ & $\begin{array}{l}\text { Verify, by referring to three flyers } \\
\text { of different shops, whether they } \\
\text { are open on Monday at 10:00 } \\
\text { o'clock. }\end{array}$ & Shopping \\
\hline $\begin{array}{l}4-\text { Using the } \\
\text { Telephone }\end{array}$ & $\begin{array}{l}\text { Make a phone call to know the } \\
\text { opening hours of the butcher } \\
\text { (number in a flyer). }\end{array}$ & Ability to use telephone \\
\hline $\begin{array}{l}5 \text { - Paying a bill } \\
\text { by check }\end{array}$ & Write a check to pay a phone bill & Ability to Handle Finances \\
\hline $\begin{array}{l}6-\text { Writing an } \\
\text { address on an } \\
\text { envelope }\end{array}$ & $\begin{array}{l}\text { Put the check in an envelope, write } \\
\text { the address and make a cross at } \\
\text { the location provided for the } \\
\text { stamp. }\end{array}$ & I \\
\hline
\end{tabular}




\begin{tabular}{|c|c|c|}
\hline $\begin{array}{l}\text { 7- Planning } \\
\text { how to relay } \\
\text { point A to point } \\
\text { B using a bus } \\
\text { plan }\end{array}$ & $\begin{array}{l}\text { Be at the post office at } 10 \text { o'clock } \\
\text { to post the envelope containing the } \\
\text { bill. A city map with two bus routes } \\
\text { and corresponding schedules is } \\
\text { presented. A red dot indicates on } \\
\text { the plan where the participant } \\
\text { resides. The task consists in } \\
\text { choosing the right bus route and } \\
\text { the appropriate time. }\end{array}$ & Mode of Transportation \\
\hline $\begin{array}{l}\text { 8-Handling } \\
\text { Money }\end{array}$ & $\begin{array}{l}\text { Give money }(8 € 60) \text { to the baker, } \\
\text { using a purse containing different } \\
\text { coins and bank notes. }\end{array}$ & Ability to Handle Finances \\
\hline $\begin{array}{l}9 \text { - Putting } \\
\text { away the } \\
\text { shopping }\end{array}$ & $\begin{array}{l}\text { Classify various items according to } \\
\text { three possible storage places } \\
\text { (refrigerator, kitchen cupboard \& } \\
\text { table). Three boards with the name } \\
\text { of the different storage location } \\
\text { and their corresponding images } \\
\text { are presented to the participant, } \\
\text { together with a list of various foods } \\
\text { and objects. }\end{array}$ & $\begin{array}{l}\text { Shopping } \\
\text { Food Preparation }\end{array}$ \\
\hline $\begin{array}{l}10-\text { Filling a } \\
\text { pillbox }\end{array}$ & $\begin{array}{l}\text { Using a prescription, the } \\
\text { participant is required to fill a } \\
\text { pillbox with fake drugs for the } \\
\text { week. }\end{array}$ & $\begin{array}{l}\text { Responsibility for own } \\
\text { medications }\end{array}$ \\
\hline $\begin{array}{l}11-\text { Taking } \\
\text { medications }\end{array}$ & $\begin{array}{l}\text { By referring to the pillbox, the } \\
\text { participant is asked three times }\end{array}$ & $\begin{array}{l}\text { Responsibility for own } \\
\text { medications }\end{array}$ \\
\hline
\end{tabular}




\begin{tabular}{|c|c|c|}
\hline & $\begin{array}{l}\text { what drugs must be taken at a } \\
\text { given day and a specific time. }\end{array}$ & \\
\hline $\begin{array}{l}12 \text { - Managing } \\
\text { accounts }\end{array}$ & $\begin{array}{l}\text { Taking into consideration a } \\
\text { cashback ticket, invoices and } \\
\text { receipts, the participant is asked to } \\
\text { calculate how much money is left } \\
\text { on his/her account. A calculator is } \\
\text { available for facilitating calculation. }\end{array}$ & Ability to Handle Finances \\
\hline $\begin{array}{l}13-\text { Household } \\
\text { activities }\end{array}$ & $\begin{array}{l}\text { The participant is asked to } \\
\text { determine what household activity } \\
\text { relates to the pictures shown. } \\
\text { This item consists of two boards } \\
\text { depicting } 3 \text { types of household } \\
\text { chores (cleaning, doing laundry } \\
\text { and washing dishes). The } \\
\text { participant is also required to } \\
\text { match } 16 \text { pictures of equipment or } \\
\text { objects with these activities. }\end{array}$ & $\begin{array}{l}\text { Housekeeping } \\
\text { Laundry }\end{array}$ \\
\hline
\end{tabular}


535 Table 3: The Area under the ROC curve (AUC) for IADL and S-IADL questionnaire 536

\begin{tabular}{|c|c|c|c|c|c|}
\hline & \multirow[t]{2}{*}{ AUC } & \multirow[t]{2}{*}{ SE } & \multicolumn{2}{|c|}{$95 \% \mathrm{Cl}$} & \multirow[t]{2}{*}{$p$} \\
\hline & & & Min & Max & \\
\hline IADL & .92 & .038 & .84 & .99 & $p<.001$ \\
\hline S-IADL & .91 & .039 & .83 & .98 & $p<.001$ \\
\hline
\end{tabular}

537

538 SE: Standard Error

539 Cl: Confidence interval

540 p: Significance level

541

542

543

544

545

546

547

548

549

550

551

552 
554

555 Figure 1: ROC Curve

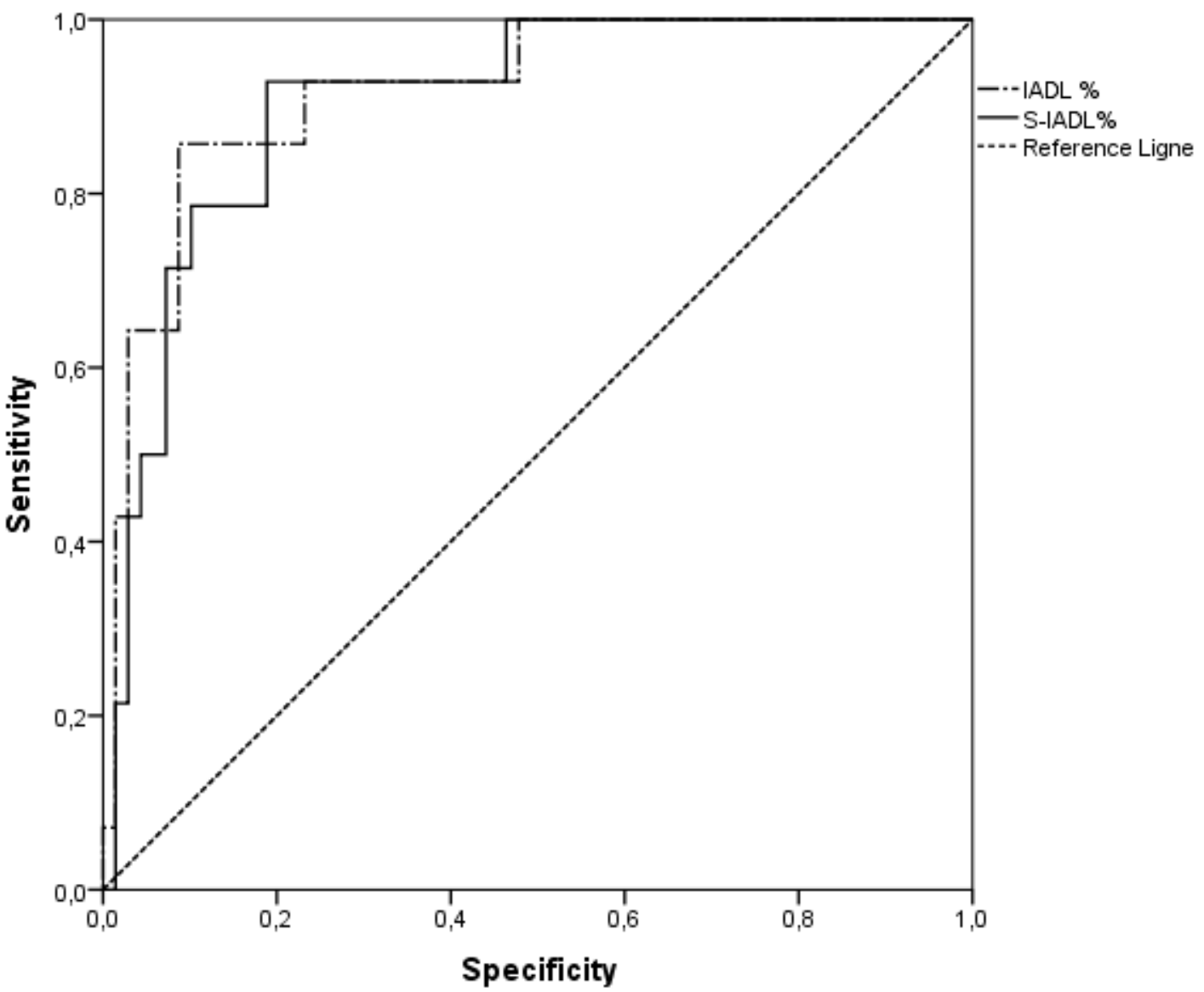

556 